\title{
Near infrared spectroscopy for evaluation of skeletal muscle tissue oxygenation in different types of shock
}

BY HUGON MOŽINA, MATEJ PODBEGAR

\section{Abstract}

Clinical examination is non-invasive, but has well-recognized limitations in detecting compensated and uncompensated low flow states and their severity.

This paper describes the principles of near infra-red spectroscopy (NIRS) and the basis for its proposed use, in hypovolaemic, cardiogenic and septic shock, for assessing global and regional tissue oxygenation. The vascular occlusion test is explained. Limitations of NIRS, current controversies, and what is necessary in the future to make this technology a part of the initial and ongoing assessment of a patient, are discussed as well. The ultimate goal of such techniques is to prevent miss-assessment and inadequate resuscitation of patients, two major initiators in the development of multisystem organ failure and death.

Key words: shock, skeletal muscle, near-infrared spectroscopy

\section{Introduction}

Oxygen delivery (DO2) is acutely reduced in all types of shock. Consequently, tissue hypoxia occurs. Sustained tissue hypoxia is one of the most important factors in the pathophysiology of organ dysfunction. (1) Maintenance of DO2 is essential to preserve organ function, and sustained low DO2 is a path to organ 
failure and death. $(2,3)$ Monitoring of global systemic and tissue oxygenation in critically ill patients appears indispensable for their treatment. (4) Cardiogenic, hypovolaemic and obstructive types of shock are characterized by decreased DO2, but a preserved oxygen extraction ratio. In septic shock, tissue oxygen extraction capability is altered so that the critical oxygen extraction ratio is typically decreased. $(2,3)$

Clinical signs of tissue perfusion adequacy (capillary refill, mottling of the skin, mental status, heart rate, pulse pressure, systemic blood pressure and urine output) are not sufficiently sensitive indicators of tissue perfusion. (5-7) Normalisation of these traditional clinical indices, after initial resuscitation, does not exclude on-going inadequate tissue perfusion. (8) The search for a more sensitive monitoring technology continues. (9) The ideal monitoring method should perform as a sensitive, early index of altered state of oxygen delivery and should also provide a goal for the treatment of low flow states, even before clinical signs are evident.

Mixed venous oxygen saturation ( $\mathrm{SvO} 2$ ) was traditionally used to estimate global tissue oxygenation (oxygen delivery/oxygen consumption (VO2) ratio). But catheterization of the pulmonary artery is costly, has inherent risks and its usefulness remains under debate. (10-12) Not surprisingly, the monitoring of central venous oxygen saturation ( $\mathrm{ScvO} 2)$ was suggested as a simpler and cheaper assessment of global DO2 to $\mathrm{VO} 2$ ratio, (13) and was used successfully as a hemodynamic goal in the treatment of patients with septic shock and severe sepsis. (14) $\mathrm{ScvO} 2$ of $70 \%$ was subsequently included in the international guidelines as a hemodynamic goal for the management of severe sepsis and septic shock. (15)

Although the relationship between systemic and peripheral circulation is not always well defined, the assessment of peripheral perfusion during peripheral cooling-induced vasoconstriction in healthy volunteers has shown that profound changes in peripheral circulation can occur independently of systemic haemodynamic parameters, such as blood pressure and cardiac output. (16) Regional perfusion changes can occur significantly earlier than traditional global indices. (17) The rationale of peripheral perfusion monitoring is based on a concept that peripheral tissues are the first to reflect hypoperfusion during shock and the last to reperfuse during resuscitation. (18) Examples of technologies which may take advantage of regional changes and which may help identify these states, include transcutaneous partial pressure of oxygen ( $\left.\mathrm{pO}_{2}\right)$ and carbon dioxide 
partial pressure (pCO2), subcutaneous and interstitial pH, pCO2, and pO2 measurements, gastric and sublingual tonometry, and near-infrared absorption spectroscopy (NIRS). (9)

\section{Principles of NIRS}

The concept of NIRS has already been available during the second half of 20 th century. (19) Visible light (450-70o nm) penetrates tissue only short distances because of strong attenuation by various tissue components. However, in the near infra-red (NIR) spectrum (7OO-1100 nm) photons are capable of deeper penetration (several centimetres or more), even through bone. Metalloproteins (haemoglobin, myoglobin and mitochondrial cytochrome oxidase) act as chromophores and absorb NIR radiation differently based on their concentration and interaction with oxygen. The Beer-Lambert law provides the physical and mathematical basis for NIRS. This law states that light passing through a solution of a coloured compound (chromophore) is absorbed by the compound resulting in a reduction in the intensity of the emerging light. (20) A probe with a near infrared light source is placed on the skin where it transilluminates tissues and detects reflected light.

The basis for the use of NIRS to monitor changes in haemoglobin (Hb) and oxyhaemoglobin ( $\mathrm{HbO}_{2}$ ), and to monitor states of tissue oxygenation, lies in the tissue compartmentalisation of blood volume, which in most organ systems is believed to be proportioned among the arteriolar, capillary, and venular compartments in a ratio of 10:20:70\% respectively. (21,22) Consequently, the majority of the NIRS signal, reflects the venous or post-extraction compartment of any particular tissue. This phenomenon provides valuable information on tissue oxygen consumption or extraction in much the same way as mixed venous haemoglobin oximetry is used from the pulmonary artery catheter. The NIR value of haemoglobin oxygen saturation from the tissue (StO2) thus represents spatially integrated information from arterioles, capillaries, and venules, which are normally weighted towards the venous compartment. Larger vessels (>1mm) are assumed to be excluded from $\mathrm{StO} 2$ determination. (23)

\section{Clinical and technical considerations in NIRS measurements}


Microcirculatory perfusion and tissue oxygen utilization are affected by sepsis and shock. $(24,25)$ These derangements can be studied non-invasively using NIRS, a technique that is able to determine the oxygenation status of tissue haemoglobin. Decreased $\mathrm{StO}_{2}$ reflects the presence of hypoperfusion and has been used clinically to guide resuscitation during hypovolaemic shock. (26) Thus, determination of regional $\mathrm{StO} 2$ might provide an early warning index of global hypoperfusion prior to significant alterations in vital signs or critical DO2 and help the clinician to verify that oxygen delivery to the tissue had been restored to a desired level.

Measurements of StO2 are noninvasive, continuous, bedside and simple. NIRS equipment is becoming light and easy to handle - all these characteristics make this method fit for emergency and critical care use.

The anatomical advantages of the thenar eminence are: the easy bedside approach; the thenar eminence can be easily subjected to the vascular occlusion test; has relatively thin skin and fat tissue over the muscle; and fibrous strands in its subcutaneous tissue limit oedema formation. All these characteristics make the thenar eminence the best possible setting for $\mathrm{StO}_{2}$ measurements, even in critically ill or obese patients.

In a human validation study, a significant correlation between NIRS measured $\mathrm{StO} 2$ and venous oxygen saturation $(\mathrm{r}=0.92, \mathrm{p}<0.05)$ was reported, where the venous effluent was obtained from a deep forearm vein that drained the exercising muscle. (27) $\mathrm{StO} 2$ was minimally affected by skin blood flow. Changes of limb perfusion affect $\mathrm{StO} 2$ : skeletal muscle $\mathrm{StO} 2$ decreases during norepinephrine and increases during nitroprusside infusion.

Choosing the right probe is crucial. The distance between the source of NIR light and the receiver of reflected light defines the depth and the volume of the transilluminated tissues under the probe. If one uses a $15 \mathrm{~mm}$ probe, penetration is only $7,5 \mathrm{~mm}$, thus the measurements will be importantly influenced by the skin and subcutaneous tissue oxygenation and will not represent skeletal muscle oxygenation. At our department we use deep penetrating probes ( $25 \mathrm{~mm}$ probes) and probes with filtering of superficial structures. (28)

The discriminatory power and predictive ability of $\mathrm{StO} 2$ can be improved by measuring the response to an ischaemic challenge. The vascular occlusion test (VOT) is a provocative test in which $\mathrm{StO} 2$ is measured at a peripheral site (such as 
the thenar eminence) whilst a transient rapid vascular occlusion is performed (above elbow cuff inflation to $260 \mathrm{mmHg}$ ) for either a defined time interval or until a pre-defined $\mathrm{StO} 2$ value is reached. During the vascular occlusion test, several $\mathrm{StO} 2$ parameters can be studied: average $\mathrm{StO} 2$ before arterial cuffing/occlusion; $\mathrm{StO} 2$ downslope during cuffing- the deoxygenation rate ( $\Delta$ down $\mathrm{StO} 2) / \mathrm{sec})$; $\mathrm{StO} 2$ upslope ( $\Delta$ up StO2)/sec); hyperaemia (overshoot of $\mathrm{StO} 2$ above baseline) (figure 1). The deoxygenation rate is a surrogate for tissue oxygen consumption. (25) $\mathrm{StO}_{2}$ and arterial oxygen saturation measured by transcutaneous pulse oxymetry can be used to calculate fractional tissue oxygen extraction according to the formula: $(\mathrm{SaO} 2-\mathrm{rStO} 2) / \mathrm{SaO} 2 .(29)$

\section{NIRS for evaluation of skeletal muscle tissue oxygenation in hypovolaemic shock}

During hypovolaemic shock, blood flow is diverted from less important tissues to vital organs leading to decreased blood flow in muscles. Activation of the sympathetic nervous system should decrease thenar muscle blood flow, with increased oxygen extraction and decreased tissue haemoglobin content. $(18,30)$ In this setting, NIRS may thus act as a sensor of the vascular response to hypovolaemia. This hypothesis was tested in trauma patients and the perioperative period.

Already in the late 1990s, at the University of Texas Houston Medical School, a team of surgical intensivists collaborated with bioengineers and health information experts to improve traumatic shock resuscitation. They tested the utility of various monitors in this process of care. One such monitor was StO2. Throughout resuscitation, skeletal muscle $\mathrm{StO}_{2}$ appeared to be quite responsive to changes in systemic DO2. SvO2 derived from the pulmonary artery (PA) catheter showed only a small rise from roughly 70 to $78 \%$ during the resuscitation process, changes in $\mathrm{StO} 2$ showed a strong correlation with changes in $\mathrm{DO} 2$, base deficit, and lactate ( $\mathrm{r}=0.95$ vs. 0.83 vs. 0.82 , respectively) but only modest correlation with $\mathrm{SvO}_{2}(\mathrm{r}=0.55)$. (26)

Furthermore, trauma patients who develop multiorgan dysfunction (MODS) or die, have a lower $\mathrm{StO}_{2}$ within 1 hour of admission, and $\mathrm{StO}_{2}$ is a stronger predictor of MODS or death than other diagnostic modalities. $(31,32)$ A low StO2 within 1 hour of admission identifies trauma patients who will require blood transfusion 
within the next 24 hours. (33)

An area of central interest in anaesthesia is the ability of NIRS measurements in the thenar muscle to detect blood loss. Data are conflicting. A 500-ml blood loss at blood donation in awake volunteers did not lead to changes in StO2. (34) A possible explanation could be that tissue haemoglobin and oxygenation at the thenar eminence are not affected by blood loss within the capacity of the compensatory mechanisms of hypovolaemia. However, $\mathrm{StO}_{2}$ during the perioperative period in cardiac surgery is lower in patients who develop certain postoperative complications. (35)

\section{NIRS for evaluation of skeletal muscle tissue oxygenation in cardiogenic shock}

Measurement of mixed venous oxygen saturation ( $\mathrm{SvO} 2)$ from the pulmonary artery is used for calculations of oxygen consumption and has been advocated as an indirect index of tissue oxygenation and prognostic predictor in critically ill patients. (36-39) We studied skeletal muscle $\mathrm{StO} 2$ in severe left heart failure with or without additional severe sepsis, and compared it with $\mathrm{SvO}$. (40) The hypothesis was that skeletal muscle $\mathrm{StO}_{2}$ could estimate $\mathrm{SvO}_{2}$ in patients with severe left heart failure and preserved oxygen extraction capability (without severe sepsis/septic shock).

In patients with severe left heart failure $(\mathrm{n}=24) \mathrm{StO} 2$ was lower than in healthy volunteers ( $58 \pm 13 \%$ and $84 \pm 4 \%$, respectively; $p<0.001)$. There was a good correlation between $\mathrm{StO}_{2}$ and $\mathrm{SvO}_{2}$ (figure 2), and between $\mathrm{SvO}_{2}$ and plasma lactate $(\mathrm{r}=0.689, \mathrm{p}=0.002, \mathrm{r}=-0.522, \mathrm{p}=0.009$, respectively). $\mathrm{StO} 2$ and $\mathrm{SvO} 2$ tracked well with each other over time, although $\mathrm{StO} 2$ overestimated $\mathrm{SvO} 2$ with a bias of $-2.3 \%$ and a precision $4.6 \%$.

The result confirmed the hypothesis that skeletal muscle $\mathrm{StO} 2$ values in patients with severe left heart failure could be used for fast non-invasive $\mathrm{SvO} 2$ estimation; and the trend of $\mathrm{StO}_{2}$ may be substituted for the trend of $\mathrm{SvO}_{2}$. $\mathrm{StO} 2$ overestimated $\mathrm{SvO}_{2}$ (bias $-2.5 \%$ ). (40) Overestimation may be due to the NIRS

method, which does not discriminate between compartments. It provides a global assessment of oxygenation in all vascular compartments (arterial, venous and capillary) in the sample volume of underlying tissue. 
Our data in patients with severe heart failure/ cardiogenic shock without severe sepsis/ septic shock are supported by previous work from Boekstegers et al. who measured the oxygen partial pressure distribution in the biceps muscle. (41) They found low peripheral oxygen availability in cardiogenic shock compared to sepsis. In cardiogenic shock, skeletal muscle oxygen partial pressure correlated with systemic oxygen delivery $(\mathrm{r}=0.59, \mathrm{p}<0.001)$ and systemic vascular resistance $(\mathrm{r}=0.74, \mathrm{p}<0.001)$. In a recently published study in patients experiencing cardiogenic shock, significant correlations between $\mathrm{StO} 2$ values and cardiac index (CI) (Spearman $\mathrm{r}=0.81 ; \mathrm{p}<$.ooo1), systemic vascular resistance index $(\mathrm{r}=-0.45 ; \mathrm{p}<$ $.0001)$, and mean arterial pressure $(\mathrm{r}=0.58 ; \mathrm{p}<.0001)$ were found. Linear regression analysis revealed that CI could be calculated using the following equation: $\mathrm{CI}=\mathrm{StO} 2 / 24.0 .(42)$

\section{NIRS for evaluation of skeletal muscle tissue oxygenation in septic shock}

In sepsis, $\mathrm{StO} 2$ values can be at the higher end of the normal spectrum $(40,43,44)$ or markedly low. $(45,46)$ In early stage septic shock, low $\mathrm{StO}_{2}$ values (i.e., $\mathrm{StO} 2<$ $75 \%$ ), when measured on the thenar eminence, specifically predict extremely low $\mathrm{ScvO} 2$ values and higher mortality. $(46,47)$

Our research group confirmed De Blasi group's findings (48) that thenar muscle tissue deoxygenation during stagnant ischaemia at admission and after haemodynamic stabilisation is significantly slower in septic shock patients compared to severe sepsis, localized infection and healthy controls. (44) The rate of StO2 decrease correlated tightly with severity of septic shock (Sequential Organ Failure Assessment score) and weakly with norepinephrine requirement, plasma lactate and C-reactive protein concentrations. The muscle tissue deoxygenation rate increased with improvement of sepsis in the septic shock and severe sepsis group. (44) These results are in accordance with those reported in a baboon septic shock model. (49) These data were interpreted as being consistent with the presence of a defect in the ability of the enzyme to accept electrons from oxygen or a limitation in the availability of the reducing equivalent. Similar results were reported in the dog gracilis muscle preparation after treating the animals with endotoxin. (50)

This local oxygen consumption limitation may be due to two different but 
cumulative mechanisms: first - a local dependency on low flow or inadequate flow conditions (46) or second - a low oxygen extraction due to mitochondrial dysfunction and/or alteration of oxygen diffusion (interstitial oedema). $(25,46,48)$ Although the mechanism involved in sepsis resuscitation is not yet fully understood, it is clear that the persistence of impaired peripheral perfusion is associated with worse patient outcomes. (51)

In the previously described study of patients with severe left heart failure, with or without additional severe sepsis/septic shock (40), we hypothesized a disagreement between $\mathrm{StO}_{2}$ and $\mathrm{SvO}_{2}$ in the group of patients with sepsis, because in patients with decreased oxygen extraction capability (with severe sepsis/septic shock), blood flowing through upper limb muscles could importantly contribute to higher venous oxygen saturation in the superior vena cava. The results confirmed the hypothesis (figure 2). $\mathrm{StO} 2$ correlated neither with $\mathrm{SvO} 2$ nor with serum lactate.

The high StO2 / low SvO2 seen in severe sepsis and septic shock, suggest blood flow redistribution. $\mathrm{StO} 2$ probably correlates with $\mathrm{ScvO} 2$ which is measured in the mixture of blood from head and both arms. (52) In healthy resting individuals $\mathrm{ScvO} 2$ is slightly lower than $\mathrm{SvO} 2$. (53) This relationship changes in periods of cardiovascular instability. Scheinman and co-workers performed the earliest comparison of $\mathrm{ScvO}_{2}$ and $\mathrm{SvO}_{2}$ in both haemodynamically stable and shocked patients . (54) In stable patients, $\mathrm{ScvO} 2$ was similar to $\mathrm{SvO} 2$. In patients with a failing heart, $\mathrm{ScvO}_{2}$ was slightly higher than $\mathrm{SvO}_{2}$ and in shock patients the difference between $\mathrm{SvO}_{2}$ to $\mathrm{ScvO} 2$ was even more expressed $(47.5 \% \pm 15.11 \%$ vs. $58.0 \% \pm 13.05 \%$, respectively, $\mathrm{p}<0.001)$. Lee and co-workers described similar findings. (55) Other more detailed studies in mixed groups of critically-ill patients designed to test if the $\mathrm{ScvO} 2$ measurements could substitute the $\mathrm{SvO}_{2}$ showed problematically large confidence limits (56) and poor correlation between the two values. (57)

The hypothesis that the slower skeletal muscle StO2 deoxygenation rate (more disturbed tissue oxygen extraction) is proportional to the $\mathrm{ScvO} 2-\mathrm{SvO} 2$ difference in patients with severe heart failure with additional sepsis/septic shock, was confirmed by our more recent study. (58) We showed that these patients had a clinically considerable $\mathrm{ScvO} 2-\mathrm{SvO} 2$ discrepancy. Monitoring $\mathrm{ScvO} 2$ is a simpler and cheaper assessment of global DO2 to oxygen consumption ratio, but its use as a treatment goal in patients with severe heart failure, with additional sepsis/septic 
shock, is questionable. Higher levels of $\mathrm{ScvO}_{2}$ in patients in the latter stages of septic shock were found in the non-survivors. (59) These findings raise concerns about high levels of $\mathrm{ScvO} 2$ in patients with septic shock. Consequently, $\mathrm{ScvO} 2$ or probably $\mathrm{StO} 2$, as a treatment goal, provides a false favourable impression of adequate body perfusion. Future studies that implement NIRS into treatment algorithms are ongoing.

\section{Summary}

The present review provides a foundation for understanding the potential value and limitations of NIRS as a tool in the assessment of patients with different types of shock. Despite continuous controversies, skeletal muscle NIRS clearly takes monitoring from a global to a local level, from invasive to non-invasive, and closer to the entrance to the hospital.

In low cardiac output states, with preserved oxygen extraction ratio (cardiogenic, hypovolaemic types of shock), StO2 measurements correlate well with invasive global indexes of oxygen delivery and consumption. In hypovolaemic shock and in the perioperative period, $\mathrm{StO}_{2}$ is a good prognostic tool. In septic shock the oxygen extraction capability is altered, and $\mathrm{StO}_{2}$ correlates better with $\mathrm{ScvO} 2$ than with $\mathrm{SvO} 2$, however, correlation coefficients are relatively low. In patients with severe sepsis and severe heart failure $\mathrm{StO}_{2}$ did not estimate $\mathrm{SvO} 2$, but, in the end, data suggest that in patients in early phase of septic shock low $\mathrm{StO}_{2}$ predicts low $\mathrm{ScvO} 2$ and higher mortality.

Dynamic StO2 monitoring, with vascular occlusion test, is a promising technique with the potential of insight into microvascular and mitochondrial function. Used in conjunction with global measures of oxygen delivery, it could provide an integrated approach to haemodynamic resuscitation in different types and phases of shock.

Figure 1. Vascular occlusion test: An original thenar saturation from the tissue (StO2) recording after arterial upper arm cuffing, and cuffing release (upper arm ischaemia reperfusion test). During the upper arm ischaemia reperfusion test, several $\mathrm{StO} 2$ parameters can be studied: average $\mathrm{StO} 2$ before arterial cuffing/occlusion; StO2 downslope during cuffing-the deoxygenation rate ( $\Delta$ down $\mathrm{StO} 2) / \mathrm{sec}$ ); $\mathrm{StO} 2$ upslope ( $\Delta \mathrm{up} \mathrm{StO2}$ )/sec); hyperaemia (overshoot of $\mathrm{StO} 2$ above baseline). Reproduced from Mozina and Podbregar. (25) 


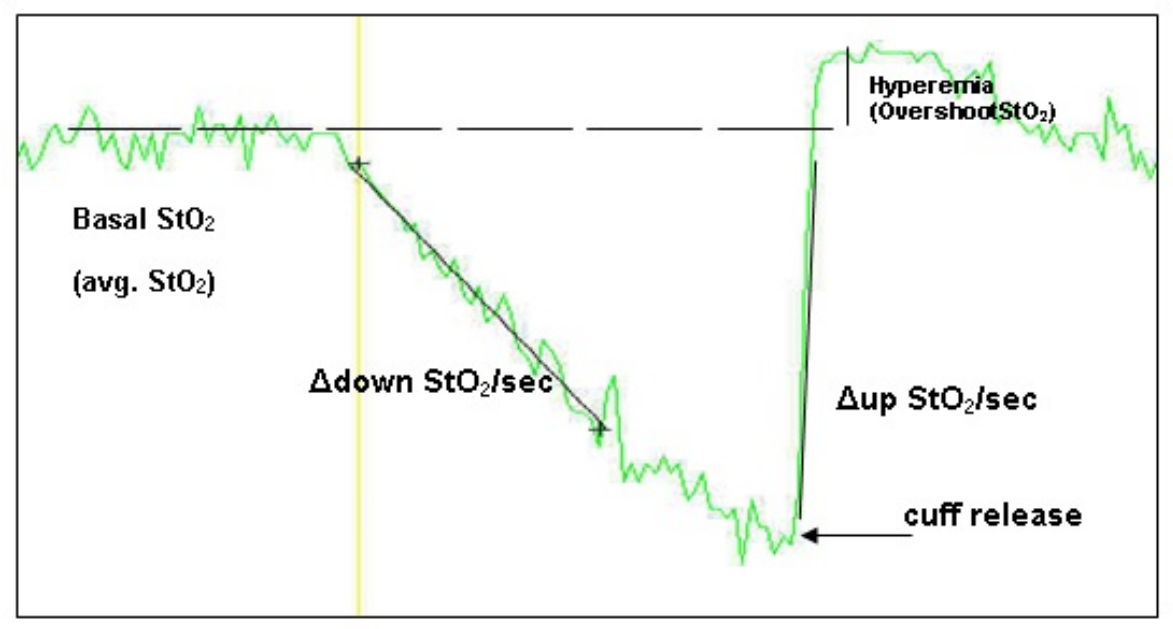

Figure 2. Correlation between skeletal muscle saturation from tissue (StO2) and mixed venous oxygen saturation ( $\mathrm{SvO} 2)$. Group A includes patients with severe left heart failure without severe sepsis/septic shock, and group B includes patients with primary heart disease and additional severe sepsis/septic shock. A statistically significant correlation was found in group A $(r=0.689, \mathrm{p}=0.002)$ but not in group $\mathrm{B}(\mathrm{r}=-0.091, \mathrm{p}=0.60)$. StO2, tissue oxygenation; $\mathrm{SvO} 2$, mixed venous oxygen saturation. Modified from Podbregar and Mozina. (40)

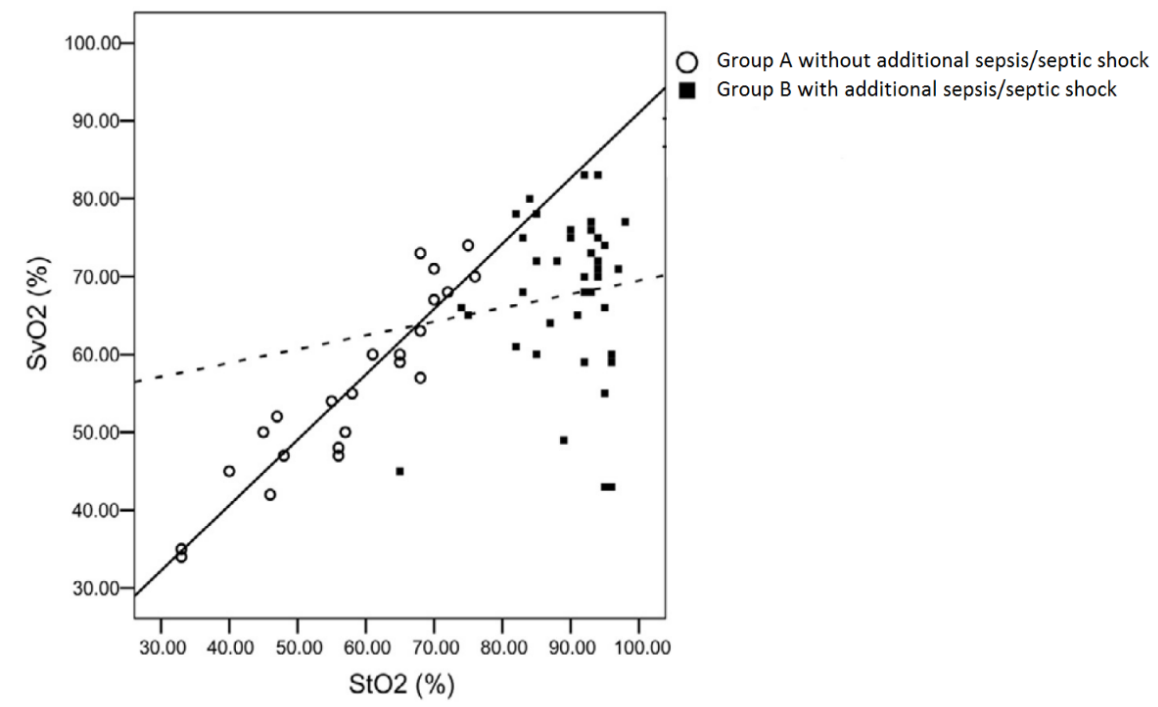

\section{References}


1. Marshall JC. Inflammation, coagulopathy, and the pathogenesis of multiple organ dysfunction syndrome. Crit Care Med 2001;29:Suppl 99-106.

2. Hameed SM, Aird WC, Cohn SM. Oxygen delivery. Crit Care Med 2003;31 Suppl 12:658-67.

3. VincentJL, De Backer D. Oxygen transport- the oxygen delivery controversy. Intensive Care Med 2004;30:1990-6.

4. Reinhart K. Monitoring $\mathrm{O}_{2}$ transport and tissue oxygenation in critically ill patients. In: Reinhart K, Eyrich K, editors. Clinical aspects of $\mathrm{O} 2$ transport and tissue oxygenation. Springer: Berlin Heidelberg New York; 1989. p. 195-211.

5. Hamiliton SM, Breakey P. Fluid resuscitation of the trauma patient: how much is enough? Can J Surg 1996;39:11-6.

6. Gosain A, Rabkin J, Reymond JP, Jensen JA, Hunt TK, Upton RA. Tissue oxygen tension and other indicators of blood loss or organ perfusion during graded hemorrhage. Surgery 1991;109:523-532.

7. Cortez A, Zito J, Lucas CE, Gerrick SJ. Mechanism of inappropriate polyuria in septic patients. Arch Surg 1977; 112: 471-6.

8. Ivatury RR, Simon RJ, Islam S, Fueg A, Rohman M, Stahl WM. A prospective randomized study of end points of resuscitation after major trauma: global oxygen transport indices versus organ-specific gastric mucosal pH.J Am Coll Surg 1996;183:145-54.

9. Trzeciak S, Rivers EP. Clinical manifestations of disordered microcirculatory perfusion in severe sepsis. Crit Care 2005;9 Suppl:20-6.

10. Dalen JE, Bone RC. Is it time to pull the pulmonary artery catheter? JAMA 1996;276: 916-8.

11. Reinhart K, Radermacher P, Sprung CL, Phelan D, Bakker J, Steltzer H. PA catheterisation - quo vadis? Do we have to change the current practice with this monitoring device. Intensive Care Med 1997;23:605 - 9.

12. The national heart, lung and blood institute Acute respiratory distress syndrome (ARDS) clinical trials network. Pulmonary-artery versus central venous catheter to guide treatment of acute lung injury. N Engl Med 2006;354:2213-24.

13. Reinhart K, Kuhn HJ, Hartog C, Bredle DL. Continuous central venous and pulmonary artery oxygen saturation monitoring in the critically ill. Intensive Care Med 2004;30:1572-8.

14. Rivers E, Nguyen B, Havstad S, Ressler J, Muzzin A, Knoblich B, et al. Early goaldirected therapy in the treatment of severe sepsis and septic shock. N EnglJ Med 2001;345:1368-77.

15. Surviving Sepsis Campaign Guidelines Management Committee. Surviving sepsis 
campaign guidelines for management of severe sepsis and septic shock. Crit Care Med 2004;32:858-73.

16. Lima A, van Genderen ME, Klijn E, Bakker J, van Bommel J. Peripheral vasoconstriction influences thenar oxygen saturation as measured by nearinfrared spectroscopy. Intensive Care Med 2012;38:606-11.

17. Guzman JA, Lacoma FJ, Kruse JA. Relationship between systemic oxygen supply dependency and gastric intramucosal $\mathrm{CO}_{2}$ during progressive hemorrhage.J Trauma 1998;44:696-700.

18. Poeze M, Solberg BC, Greve JW, Ramsay G. Monitoring global volume related hemodynamic or regional variables after initial resuscitation: what is a better predictor of outcome in critically ill septic patients? Crit Care Med 2005;33:2494500 .

19. Jobsis FF. Noninvasive, infrared monitoring of cerebral and myocardial oxygen sufficiency and circulatory parameters. Sience 1977; 198: 1264-1267.

20. Owen-Reece H, Smith M, Elwell CE, Goldstone JC. Near infrared spectroscopy. Br J Anaesth 1999;82:418-26.

21. Guyton AC. The systemic circulation. In: Guyton AC, editor. Textbook of medical physiology. 6th ed. Philadelphia: W.B. Saunders; 1981. p. 219-25.

22. Shepherd JT. Circulation to skeletal muscle. In: Shepherd JT, Abboud FM, Geiger SR, editors. Handbook of physiology. Bethesda, MD: American Physiology Society; 1983. p. 319-70.

23. McCully KK, Hamaoka T. Near-infrared spectroscopy: what can it tell us about oxygen saturation in skeletal muscle? Exerc Sport Sci Rev 2000;28:123-7.

24. Spronk PE, Zandstra DF, Ince C. Bench-to-bedside review: sepsis is a disease of the microcirculation. Crit Care 2004;8:462-8.

25. Mozina H, Podbregar M. Near-infrared spectroscopy for evaluation of global and skeletal muscle tissue oxygenation. World J of cardiol 2011;12:377-82.

26. McKinley BA, Marvin RG, Cocanour CS, Moore FA. Tissue hemoglobin O2 saturation during resuscitation of traumatic shock monitored using near infrared spectrometry. J Trauma 2000;48:637-42.

27. Mancini DM, Bolinger L, Li H, Kendrick K, Chance B, Wilson JR. Validation of near-infrared spectroscopy in humans. J Appl Physiology 1994;77:2740-7.

28. Podbregar M. Thenar tissue oxygen saturation monitoring: Noninvasive does not mean simple or accurate! Letter to the editor. Crit Care Med 2012;40:712-3.

29. Znidarsic Erzen M, Jelic M, Gornik A, Podbregar M, Grosek S. Near infrared spectroscopy tissue oxygenation in infants with bronchiolitis during mechanical ventilation and spontaneous breathing. Signa Vitae 2014;9:15-24. 
30. McKinley BA, Parmley CL, Butler BD. Skeletal muscle PO2, $\mathrm{PCO}$, and pH in hemorrhage, shock, and resuscitation in dogs. J Trauma 1998;44:119-27.

31. Moore FA, Nelson T, McKinley BA, Moore EE, Nathens AB, Rhee P, et al. Massive transfusion in trauma patients: tissue hemoglobin oxygen saturation predicts poor outcome. J Trauma 2008;64:1010-23.

32. Cohn SM, Nathens AB, Moore FA, Rhee P, Puyana JC, Moore EE, et al. Tissue oxygen saturation predicts the development of organ dysfunction during traumatic shock resuscitation. J Trauma 2007;62:44-54.

33. SmithJ, Bricker S, Putnam B. Tissue oxygen saturation predicts the need for early blood transfusion in trauma patients. Am Surg 2008;74:1006-11.

34. Jeger V, Jakob SM, Fontana S, Wolf M, Zimmermann H, Exadaktylos AK. $500 \mathrm{ml}$ of blood loss does not decrease non-invasive tissue oxygen saturation (StO2) as measured by near infrared spectroscopy - A hypothesis generating pilot study in healthy adult women. J Trauma Manag Outcomes 2010;4:5.

35. Sanders J, Toor IS, Yurik TM, Keogh BE, Mythen M, Montgomery HE. Tissue oxygen saturation and outcome after cardiac surgery. Am J Crit Care 2011;20:13845 .

36. Goldman RH, Klughaupt M, Metcalf T, Spivak AP, Harrison DC. Measurement of central venous oxygen saturation in patients with myocardial infarction. Circulation 1968;38:941-946.

37. Kasnitz P, Druger GL, Zorra F, Simmons DH. Mixed venous oxygen tension and hyperlactemia. Survival in severe cardiopulmonary disease. JAMA 1976;236:570-574.

38. Krafft P, Steltzer H, Hiesmayr M, Klimscha W, Hammerle AF. Mixed venous oxygen saturation in critically ill septic shock patients. The role of defined events. Chest 1993;103: 900-906.

39. Edwards JD. Oxygen transport in cardiogenic and septic shock. Crit Care Med 1991, 19: 658-663.

40. Podbregar M, Mozina H. Skeletal muscle oxygen saturation dose not estimate mixed venous oxygen saturation in patients with severe left heart failure and additional severe sepsis or septic shock. Critical Care 2007;11:R6.

41. Boekstegers P, Weidenhofer S, Pilz G, Werdan K. Peripherial oxygen availability within skeletal muscle in sepsis and septic shock: comparison to limited infection and cardiogenic shock. Infection 1991;19:317-23.

42. Ostadal P, Kruger A, Vondrakova D, Janotka M, Psotova H, Neuzil P. Noninvasive assessment of hemodynamic variables using near-infrared spectroscopy in patients experiencing cardiogenic shock and individuals undergoing venoarterial extracorporeal membrane oxygenation. J Crit Care 2014;29:690. 
43. Strahovnik I, Podbregar M. Measurement of skeletal muscle tissue oxygenation in the critically ill. Signa Vitae 2008;3:43-50.

44. Pareznik R, Voga G, Knezevic R, Podbregar M. Changes of muscle tissue oxygenation during stagnant ishemia in septic patients. Intensive Care Med 2006; 32; 87-92.

45. Lipcsey M, Woinarski NCZ, Bellomo R. Near infrared spectroscopy (NIRS) of the thenareminence in anesthesia and intensive care. Annals of Intensive Care 2012;2:11-20.

46. Mesquida J, Gruartmoner G, Martínez ML, Masip J, Sabatier G, Espinal C, et al. Thenar oxygen saturation and invasive oxygen delivery measurements in critically ill patients in early septic shock. Shock 2011;35:456-9.

47. Colin G, Nardi O, Polito A, Aboab J, Maxime V, Clair B, et al. Masseter tissue oxygen saturation predicts normal central venous oxygen saturation during early goal-directed therapy and predicts mortality in patients with severe sepsis. Crit Care Med 2012;40:435-40.

48. De Blasi RA, Palmisani S, Alampi D, Mercieri M, Romao R, Collini S, et al. Microvascular dysfunction and skeletal muscle oxygenation assessed by phasemodulation near-infrared spectroscopy in patients with septic shock. Intensive Care Med 2005;31:1661-8.

49. Simonson SG, Welty-Wolf K, Huang YT, Griebel JA, Caplan MS, Fracica PJ, et al. Altered mitochondrial redox responses in gram negative septic shock in primates. Circ Shock 1994;43:34-43.

50. Duhaylongsod FG, Griebel JA, Bacon DS, Wolfe WG, Piantadosi CA. Effects of muscle contraction on cytochrome a,a3 redox state. J Appl Physiol 1993;75:790-7.

51. Lima A, Jansen TC, van Bommel J, Ince C, Bakker J. The prognostic value of the subjective assessment of peripheral perfusion in critically ill patients. Crit Care Med 2009;37:934-8.

52. Nardi O, Gonzalez H, Fayssoil A, Annane D. Masseter muscle oxygen saturation is associated with central venous oxygen saturation in patients with severe sepsis. J Clin Monit Comput 2010;24:289-3.

53. Barratt-Boyes BG, Wood EH. The oxygen saturation of blood in the venae cavae, right-heart chambers, and pulmonary vessels of healthy subjects. J Lab Clin Med 1957;50:93-106.

54. Scheinman MM, Brown MA, Rapaport E. Critical assessment of use of central venous oxygen saturation as a mirror of mixed venous oxygen in severely ill cardiac patients. Circulation 1969;40:165-72.

55. Lee J, Wright F, Barber R, Stanley L. Central venous oxygen saturation in shock: a 
study in man. Anesthesiology 1972; 36: 472-8.

56. Edwards JD, Mayall RM. Importance of the sampling site for measurement of mixed venous oxygen saturation in shock. Crit Care Med 1998;26:1356-6o.

57. Martin C, Auffray JP, Badetti C, Perrin G, Papazian L, Gouin F. Monitoring of central venous oxygen saturation versus mixed venous oxygen saturation in critically ill patients. Intensive Care Med 1992;18:101-4.

58. Mozina H, Podbregar M. Near-infrared spectroscopy during stagnant ischaemia estimates central venous oxygen saturation and mixed venous oxygen saturation discrepancy in patients with severe left heart failure and additional sepsis/septic shock. Crit Care 2010;14: R42.

59. Textoris J, Fouché L, Wiramus S, Antonini F, Tho S, Martin C, et al. High central venous oxygen saturation in the latter stages of septic shock is associated with increased mortality. Critical Care 2011;15:R176.

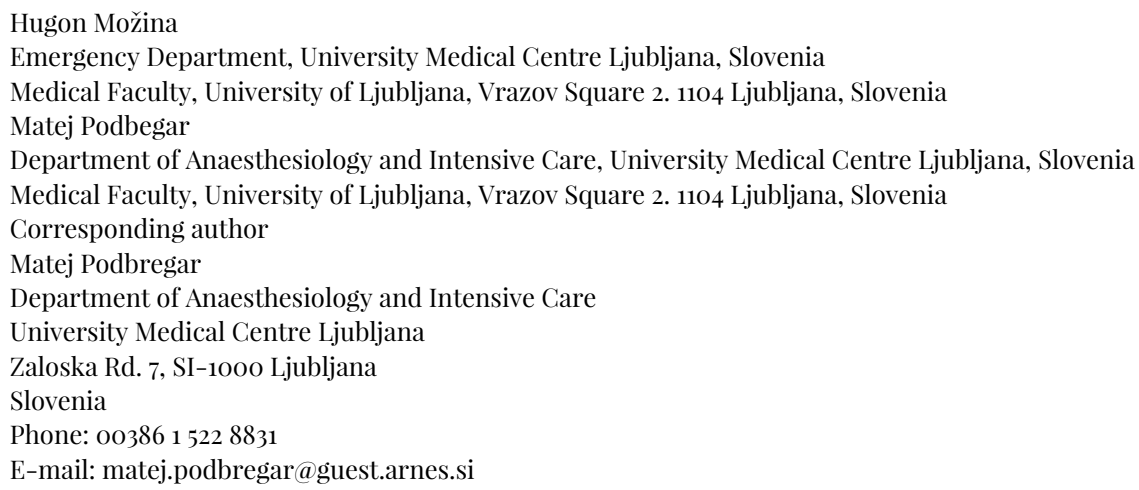

